\title{
Níveis de Lisina para Leitoas Selecionadas Geneticamente para Deposição de Carne Magra, dos 60 aos $95 \mathrm{~kg}^{1}$
}

\author{
Dalton de Oliveira Fontes ${ }^{2}$, Juarez Lopes Donzele ${ }^{3}$, Aloisio Soares Ferreira $^{3}$, Rita Flávia \\ Miranda de Oliveira ${ }^{3}$, Carlos Alberto Gil Gomes Júnior ${ }^{4}$
}

\begin{abstract}
RESUMO - Foram utilizadas 50 leitoas mestiças (Hampshire, Landrace Belga, Pietran) com peso inicial médio de 60,23 $\pm 0,49 \mathrm{~kg}$ e alto potencial genético para deposição de carne magra na carcaça, para avaliar diferentes níveis de lisina. Foi usado delineamento de blocos ao acaso com cinco tratamentos, cinco repetições e dois animais por unidade experimental. Os tratamentos corresponderam a uma ração basal com 15,8\% de proteína bruta, suplementada com cinco níveis de L-lisina $\mathrm{HCl}$, resultando em rações com 0,75; 0,85; 0,95; 1,05; e $1,15 \%$ de lisina. Não se observou efeito dos tratamentos sobre consumo de ração e ganho de peso diário, entretanto, o consumo de lisina diário elevou-se de forma linear com o aumento do nível de lisina da ração. Houve efeito quadrático dos níveis de lisina sobre a conversão alimentar e o teor de uréia no soro sangüíneo, que reduziram até o nível de 1,00\% de lisina ou 0,302\% /Mcal de ED, o que correspondeu a um consumo estimado de lisina de 23,90 g/dia. Não se observou efeito dos tratamentos sobre a porcentagem de água e proteína e taxa de deposição de proteína na carcaça, entretanto, a porcentagem e a taxa de deposição de gordura diminuíram de maneira linear. Concluiu-se que leitoas com alto potencial genético para deposição de carne magra, dos 60 aos $95 \mathrm{~kg}$ de peso vivo, requerem $1,00 \%$ de lisina $(0,302 \%$ /Mcal de ED) e $0,90 \%$ (0,272\%/Mcal de ED) de lisina digestível verdadeira, para máximo desempenho, o que corresponde a consumo diário de lisina total e digestível de 23,9 e 21,5 g, respectivamente.
\end{abstract}

Palavras-chave: carcaça, exigência, fase de terminação, genótipo, uréia

\section{Lysine Levels for Gilts with High Genetic Potential for Lean Meat Deposition from 60 to $95 \mathrm{~kg}$}

\begin{abstract}
Fifty gilts crossbreed (Hampshire, Belgium Landrace, Pietran), with initial average weight of $60.23 \pm 0.49 \mathrm{~kg}$ and high genetic potential for lean meat deposition, were used to evaluate different lysine levels. A randomized blocks design, with five treatments, five replicates and two animals per experimental unit, was used. The treatments corresponded to a basal diet with $15.8 \%$ crude protein, supplemented with five levels of HCl-L-Lisine, resulting in diets with $0.75,0.85,0.95,1.05$, and $1.15 \%$ of lysine. There was no effect of treatments on daily weight gain and daily feed intake, however daily lysine intake linearly increased was the dietary lysine level increased. There was quadract effect of lysine levels on feed:gain ratio and on serum urea concentration, that increased up to the lysine level of $1.00 \%$ or $0.302 \% / \mathrm{Mcal}$ of DE, corresponding to a estimate lysine intake of $23.9 \mathrm{~g} / \mathrm{day}$. There was no effect of treatments on protein and water percent, and protein deposition in carcass, however, the percentage of fat and fat deposition rate linearly decreased. The gilts with high genetic potential for lean meat deposition, from 60 to $95 \mathrm{~kg}$, had requirement of $1.00 \%$ (.302\%/Mcal of DE) or .90\% (.272\%/Mcal of DE) of true digestible lysine, corresponding to total and digestible lysine intake of 23.90 and $21.50 \mathrm{~g} /$ day, respectively, for maximum performance.
\end{abstract}

Key Words: carcass, genotype, requirement, finishing phase, urea

\section{Introdução}

Suínos com elevada capacidade para deposição de carne magra requerem, diariamente, maiores quantidades de lisina para maximizar seu desempenho e taxa de deposição de proteína na carcaça. Essas diferenças podem ser observadas nas diferentes fases de crescimento, sendo bem evidentes nas fases de crescimento e terminação (STAHLY et al., 1991;
STAHLY et al., 1994; FRIESEN et al., 1994; e FRIESEN et al., 1995).

FRIESEN et al. (1995) observaram que leitoas com alto potencial genético para deposição de carne magra, dos 72 aos $104 \mathrm{~kg}$, requerem $0,94 \%$ de lisina digestível, para máximo ganho de peso e eficiência alimentar, o que representa aumento de $30 \%$ nas estimativas do NATIONAL RESEARCHCOUNCIL - NRC (1998) para suínos dos 50 aos 80 kg. Do

\footnotetext{
${ }^{1}$ Parte da tese de Doutorado do primeiro autor. Projeto financiado pela FAPEMIG.

2 Professor da UFMG

3 Professor do DZO/UFV.

${ }^{4}$ Bolsista de Iniciação Científica DZO/UFV.
} 
mesmo modo, STAHLY et al. (1991) observaram que o aumento do nível de lisina dietética elevou o ganho de peso diário, a eficiência alimentar e o ganho de carne na carcaça nos genótipos superiores, nas fases de crescimento e terminação.

Nesse sentido, o NRC (1998) sugere níveis diferenciados de lisina para leitoas dos 50 aos $120 \mathrm{~kg}$, de acordo com seu potencial genético para deposição de carne magra na carcaça, de forma que diferentes planos de nutrição possam ser estabelecidos para os diferentes genótipos.

Entretanto, ainda são escassos os dados na literatura sobre os requerimentos nutricionais de lisina de suínos com alto potencial genético para deposição de carne magra na carcaça, na fase de terminação.

Além do método de dose-resposta, comumente utilizado para determinação dos requerimentos nutricionais dos animais, o modelo fatorial tem sido usado para estimar os requerimentos de energia, proteína e aminoácidos para os diferentes genótipos. Segundo Moughan (1989), citado por CLOSE (1994), esse método tem sido considerado mais flexível e apropriado para essa finalidade.

O objetivo deste trabalho foi avaliar o efeito de níveis de lisina sobre desempenho, nível de uréia no soro sangüíneo e composição e taxas de deposição de gordura e proteína na carcaça de leitoas com alto potencial genético para produção de carne magra, dos 60 aos $95 \mathrm{~kg}$ de peso vivo.

\section{Material e Métodos}

\section{Local e instalações}

O experimento foi conduzido no Setor de Suinocultura do Departamento de Zootecnia da Universidade Federal de Viçosa.

Os animais foram alojados em baias contendo comedouros semi-automáticos e bebedouros tipo chupeta, em galpão de alvenaria com piso de concreto e coberto com telhas de barro. Foi utilizado um termômetro de máxima e mínima, colocado no interior do galpão, para registro diário da temperatura. As temperaturas médias das mínimas e das máximas verificadas no período foram, respectivamente, $20,7 \pm 1,36^{\circ} \mathrm{Ce} 28,1 \pm 2,12^{\circ} \mathrm{C}$.

\section{Animais e delineamento experimental}

Foram utilizadas 50 leitoas mestiças (Pietran, Landrace Belga e Hampshire), com peso inicial médio de 60,2 $\pm 0,49 \mathrm{~kg}$, distribuídas em delineamento experimental de blocos ao acaso, com cinco tratamentos $(0,75$; 0,$85 ; 0,95 ; 1,05 ;$ e $1,15 \%$ de lisina na ração), cinco repetições e dois animais por unidade experimental. Os blocos foram formados no tempo, tendo cada bloco duração média de 36,6 $\pm 0,8$ dias. $\mathrm{Na}$ distribuição dos animais, dentro de cada bloco, adotaram-se, como critério, o peso inicial e o parentesco dos animais.

$\mathrm{Na}$ ocasião, um adicional de cinco animais, da mesma linhagem, com peso médio de $61,2 \pm 1,64 \mathrm{~kg}$, foi abatido para determinar a composição da carcaça dos suínos no início do experimento.

\section{Dietas e manejo alimentar}

Os tratamentos corresponderam a uma ração basal (Tabela 1) com 15,8\% de proteína bruta e 3315 kcal de ED, formulada de modo a exceder as recomendações nutricionais mínimas sugeridas pelo NRC (1988), suplementada com cinco níveis de L-LisinaHCl 78,4\% (0,000; 0,127; 0,255; 0,382; e 0,510\%), em substituição ao caulim, resultando em rações experimentais (Tabela 2) com um total de 0,$75 ; 0,85 ; 0,95$; 1,05 ; e $1,15 \%$ de lisina, sendo fornecidas à vontade

Tabela 1 - Composição da ração basal (\%) Table 1 - Composition of the basal diet

\begin{tabular}{|c|c|}
\hline $\begin{array}{l}\text { Ingrediente } \\
\text { Ingredient }\end{array}$ & $\begin{array}{c}\text { Ração basal } \\
\text { Basal diet }\end{array}$ \\
\hline $\begin{array}{l}\text { Milho (Corn) } \\
\text { Farelo de soja (Soybean meal) } \\
\text { Fosfato bicálcico (Dicalcium phosphate) } \\
\text { Calcário(Limestone) } \\
\text { Caulim } \\
\text { Sal(Salt) } \\
\text { Premix mineral }^{1} \text { (Mineralmix) }^{1} \\
\text { Premix vitamínico }{ }^{2} \text { (Vitamin mix) } \\
\text { Bacitracina de zinco (Zinc bacitracin) } \\
\text { Antioxidante- BHT (Antioxidant-BHT) } \\
\text { DL-Metionina (99\%) (DL- Methionine } 99 \%) \\
\text { L-Treonina }(98,5 \%)(\text { L-Threonine } 98.5 \%) \\
\text { L-Triptofano (99\%) (L-Tryptophan-99\%) }\end{array}$ & $\begin{array}{r}75,11 \\
20,44 \\
1,16 \\
1,03 \\
1,41 \\
0,34 \\
0,05 \\
0,10 \\
0,05 \\
0,01 \\
0,118 \\
0,171 \\
0,005\end{array}$ \\
\hline \multicolumn{2}{|l|}{$\begin{array}{l}\text { Composição calculada } \\
\text { Calculated composition }\end{array}$} \\
\hline $\begin{array}{l}\text { Energia digestível (kcal/kg) } \\
\text { Digestible energy }\end{array}$ & 3315 \\
\hline $\begin{array}{l}\text { Proteína bruta }(\%) \\
\text { Crude protein }\end{array}$ & 15,8 \\
\hline $\begin{array}{l}\text { Cálcio }(\%) \\
\text { Calcium } \\
\text { Fósforo disponível (\%) } \\
\text { Available phophorus }\end{array}$ & 0,75 \\
\hline \multicolumn{2}{|c|}{ 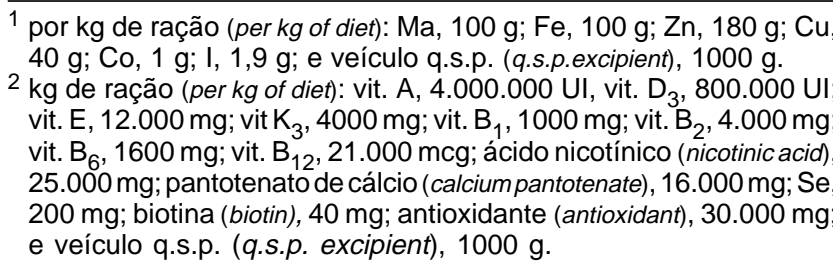 } \\
\hline
\end{tabular}


Rev. bras. zootec.

Tabela 2 - Composição em aminoácidos totais dos ingredientes e em aminoácidos totais e digestíveis da ração basal ${ }^{1}$

Table 2 - Composition in total amino acids of ingredients and in total and digestible amino acids of basal diet

\begin{tabular}{|c|c|c|c|c|c|}
\hline \multirow[t]{2}{*}{$\begin{array}{l}\text { Aminoácido } \\
\text { Amino acid }\end{array}$} & \multirow{2}{*}{$\begin{array}{l}\text { Milho } \\
\text { Corn } \\
\text { AAT } 1,2\end{array}$} & \multirow{2}{*}{$\begin{array}{l}\text { Farelo de soja } \\
\text { Soybean meal } \\
\qquad \text { AAT }^{1,2}\end{array}$} & \multicolumn{3}{|c|}{$\begin{array}{l}\text { Ração basal } \\
\text { Basal diet }\end{array}$} \\
\hline & & & AAT 1,2 & $\mathrm{AADV}^{3}$ & $\mathrm{AADA}^{4}$ \\
\hline Lisina & 0,23 & 2,82 & 0,750 & 0,648 & 0,611 \\
\hline Metionina & 0,16 & 0,54 & 0,231 & 0,214 & 0,201 \\
\hline Met + Cist & \multicolumn{5}{|c|}{$M e t+C y s$} \\
\hline Threonine & 0,26 & 1,49 & 0,673 & 0,587 & 0,556 \\
\hline Isoleucina & \multicolumn{5}{|c|}{ Isoleucine } \\
\hline Arginina & 0,33 & 3,88 & 1,043 & 1,012 & 0,982 \\
\hline Valina & \multicolumn{5}{|c|}{ Valine } \\
\hline $\begin{array}{l}\text { Triptofano } \\
\text { Triptophan }\end{array}$ & 0,05 & 0,72 & 0,190 & 0,167 & - \\
\hline Leucina & \multicolumn{5}{|c|}{ Leucine } \\
\hline $\begin{array}{l}\text { Fenilalanina } \\
\text { Fenilalanine } \\
\text { Histidina }\end{array}$ & 0,47 & - & - & - & - \\
\hline \multicolumn{6}{|l|}{ Histidine } \\
\hline $\begin{array}{l}\text { Tirosina } \\
\text { Tirosine }\end{array}$ & 0,29 & - & - & - & \\
\hline \multicolumn{6}{|c|}{1 Aminoácidos determinados no analisador de aminoácidos HITACHI MOD. 8500A } \\
\hline \multicolumn{6}{|c|}{$\begin{array}{l}\text { 3,4 Aminoácido digestível verdadeiro e aparente, respectivamente - determinado em suínos submetidos à anastomose } \\
\text { íleo-retal término-terminal. }\end{array}$} \\
\hline \multicolumn{6}{|c|}{ nined in the amino acids analyzer HITACHIMOD. 8500A } \\
\hline 3,4 True and app & & $y$, determined in & d to en & anos & thod. \\
\hline
\end{tabular}

durante todo período experimental.

A composição dos ingredientes em aminoácidos totais, utilizados nas rações experimentais, e a composição da ração basal em aminoácidos totais e digestíveis encontram-se na Tabela 2. A digestibilidade dos aminoácidos sintéticos adicionados à ração foi considerada $100 \%$.

As rações foram pesadas semanalmente, enquanto os animais foram pesados no início e no final do período experimental, quando atingiram, em média, 95,2 $\pm 3,2 \mathrm{~kg}$ de peso, para determinação do consumo de ração e lisina, do ganho de peso e da conversão alimentar.

\section{Ensaio de digestibilidade}

Para determinação da digestibilidade verdadeira dos aminoácidos da ração basal, três suínos de $20,7 \pm 4,3 \mathrm{~kg}$ foram submetidos à anastomose íleoretal, segundo metodologia descrita por LOPES et al. (1998). O ensaio de digestibilidade foi realizado em gaiolas de metabolismo localizadas em sala climatizada, na qual a temperatura ambiente foi mantida a $22^{\circ} \mathrm{C}$, sendo monitorada por meio de termômetro de máxima e mínima, mantido à meia altura do corpo dos animais.

Os animais tiveram um período de adaptação de cinco dias, quando foi verificado o consumo individual de ração. O período de coleta teve duração de cinco dias, quando os animais receberam ração experimental umedecida (1:1), às 8 e $16 \mathrm{~h}$, sendo a quantidade fornecida diariamente com base no consumo por peso metabólico $\left(\mathrm{kg}^{0,75}\right)$. As rações experimentais continham $0,5 \%$ óxido crômico, utilizado como indicador na determinação da digestibilidade. Após consumir toda a ração experimental, os animais receberam água à vontade.

A coleta de digesta foi feita duas vezes ao dia, logo após o fornecimento das rações experimentais, sendo o volume total de digesta produzida 
homogeneizado e pesado. Posteriormente, uma amostra de aproximadamente $20 \%$ de cada coleta foi retirada e armazenada a $-12^{\circ} \mathrm{C}$ em sacos plásticos devidamente identificados, para as análises posteriores.

Os teores de matéria seca e cromo na ração basal e nas digestas foram determinados no Laboratório de Nutrição Animal do Departamento de Zootecnia da Universidade Federal de Viçosa, de acordo com metodologia descrita por SILVA (1990).

Os valores das perdas endógenas dos aminoácidos e do fator de indigestibilidade da dieta isenta de proteína, utilizados para os cálculos dos coeficientes de digestibilidade verdadeira dos aminoácidos, basearam-se nos dados obtidos por POZZA (1998), utilizando a metodologia da dieta isenta de proteína, com leitões de $22 \pm 2,3 \mathrm{~kg}$.

As análises dos aminoácidos na ração basal, nos ingredientes (milho, farelo de soja e glúten de milho) e nas excretas foram realizadas no Laboratório da Guabi - Mogiana Alimentos S/A - Campinas, SP, utilizando-se o analisador de aminoácidos HITACHI modelo $8500 \mathrm{~A}$.

Foram determinados os valores da digestibilidade ileal aparente e verdadeira, que foram calculados com base nos níveis de cromo (Cr), nas rações e nas digestas, por meio do cálculo do fator de indigestibilidade (FI), utilizando-se as fórmulas descritas por ROSTAGNO e FEATHERSTON (1977).

Avaliação de uréia no soro, procedimento de abate e análises de carcaça

No final do experimento, um animal de cada unidade experimental, após jejum alimentar de 24 horas, recebeu ração experimental à vontade por uma hora. Após esse período, os animais retornaram ao jejum alimentar e hídrico por mais cinco horas, quando, logo em seguida, se coletou o sangue dos animais, por meio de punção no sinus orbital. O sangue coletado foi, em seguida, centrifugado, durante 10 minutos, para retirada do soro, que foi estocado em congelador. Posteriormente, procedeu-se às determinações da uréia por meio de "kits de determinação LABTEST", em equipamento Vitek Systems, AXIA 2, bioMérieux.

O outro animal de cada unidade experimental foi abatido, após ter sido submetido a jejum alimentar de 24 horas, com jejum hídrico nas últimas 12 horas.

Os animais foram abatidos por sangramento, depilados com lança-chamas e faca e, após, eviscerados. As carcaças inteiras, incluindo cabeça e pés, foram pesadas. Posteriormente, a metade esquerda das carcaças foi triturada por $20 \mathrm{~min}$ em "CUTTER" comercial de 30 HP e 1775 revoluções por minuto e, após homogeneização, foram retiradas amostras que foram conservadas a $-12^{\circ} \mathrm{C}$.

Em razão da alta concentração de água e gordura na carcaça dos animais, as amostras foram submetidas, inicialmente, à pré-secagem em estufa com ventilação forçada a $60^{\circ} \mathrm{C}$, por 96 horas, seguida de pré-desengorduramento pelo método a quente, por quatro horas, em extrator tipo "SOXHLET". As amostras pré-secas e pré-desengorduradas foram então moídas em moinho de bola, acondicionadas em vidros e conservadas em geladeira, para análises posteriores.

A água e a gordura retiradas durante o preparo inicial das amostras foram consideradas para correções dos valores das análises subseqüentes. As análises de água, proteína bruta e gordura das amostras foram realizadas de acordo com SILVA (1990).

As taxas de deposição de proteína e gordura nas carcaças foram calculadas comparando-se as composições das carcaças dos animais no início e no fim do período experimental.

\section{Análises estatísticas}

As variáveis de desempenho, os níveis de uréia no soro dos animais, a composição de carcaça e as taxas de deposição de proteína e gordura nas carcaças foram submetidos à análise de variância utilizando-se o Sistema de Análise Estatística e Genéticas-SAEG (UFV, 1997).

A estimativa da exigência de lisina foi realizada com base nos resultados obtidos, utilizando-se os modelos de regressão linear e quadrático.

Para determinação da exigência de lisina digestível, foi considerado o coeficiente de digestibilidade verdadeira de lisina da ração basal, determinado no experimento de digestibilidade.

\section{Modelo fatorial}

Os dados de taxas de deposição de proteína e gordura na carcaça foram utilizados nas equações sugeridas por BIKKER e BOSCH (1996), para estimar o requerimento de lisina digestível e avaliar a consistência dos dados de exigência obtidos pelo método tradicional (dose-resposta), utilizado neste trabalho, com os estimados por aquelas equações.

A equação para estimar o requerimento de lisina digestível sugerida por BIKKER e BOSCH (1996), descrita abaixo, baseou-se no - AGRICULTURE RESEARCH COUNCIL - ARC (1981) e em FULLER e WANG (1987):

$$
\text { (1) }-\operatorname{Lis}_{r e q}(g / d)=\operatorname{Lis}_{m}+\left(\mathrm{TDP} * \operatorname{Lis}_{\mathrm{pr}}\right) / \mathrm{e}
$$


788 Rev. bras. zootec.

em que Lis ${ }_{\mathrm{m}}=$ lisina para mantença $(\mathrm{g} / \mathrm{d})=0,036$ * $\mathrm{PC}^{0,75} ; \mathrm{TDP}=$ taxa de deposição de proteína $(\mathrm{g} / \mathrm{d})$; Lis $_{\mathrm{pr}}=$ lisina na proteína corporal $(\mathrm{g} / \mathrm{g})=0,07(7 \%)$; $\mathrm{e}=$ eficiência de utilização de lisina $=0,7(70 \%)$.

Para estimativa do requerimento de lisina digestível em g/Mcal de ED, BIKKER e BOSCH (1996) sugerem a utilização da equação estabelecida pelo ARC (1981), em que o requerimento de energia metabolizável é estimado segundo a equação:

(2) $-\mathrm{EMc}=\mathrm{EMm}+1 / \mathrm{k}_{\mathrm{p}} * \mathrm{P}+1 / \mathrm{kg} * \mathrm{G}$

em que $\mathrm{EMc}=$ consumo de $\mathrm{EM}(\mathrm{Mcal} / \mathrm{dia}) ; \mathrm{EMm}=$ requerimento de $\mathrm{EM}$ para mantença $\left(\mathrm{kcal} / \mathrm{kg} \mathrm{PC}{ }^{0,75}\right)$ $=131,35 \mathrm{kcal} / \mathrm{kg} ; \mathrm{P}=$ energia retida como proteína $=$ TDP $* 5,66 \mathrm{kcal} / \mathrm{g} ; \mathrm{G}=$ energia retida como gordura $=\mathrm{TDG}_{*} 9,46 \mathrm{kcal} / \mathrm{g} ; \mathrm{k}_{\mathrm{p}}=$ eficiência de utilização da energia para deposição de proteína $=0,54(54 \%)$; e kg = eficiência de utilização da energia para deposição de gordura $=0,74(74 \%)$.

Dividindo-se a equação (1) pela (2) calculouse o requerimento de lisina em grama/Mcal de ED (Q), conforme proposto por BIKKER e BOSCH (1996), de acordo com a fórmula abaixo:

(3) $\mathrm{Q}=(1) *(1000 * 0,96) /(2)$

em que 0,96 é o fator de conversão dos dados de EM para ED.

\section{Resultados e Discussão}

Os resultados de ganho de peso, conversão alimentar, consumo de ração e de lisina e teor de uréia no soro sangüíneo de leitoas dos 60 a $95 \mathrm{~kg}$ são apresentados na Tabela 3.

Não se observou efeito $(\mathrm{P}>0,05)$ dos níveis de lisina da dieta sobre o consumo de ração diário (CRD) e o ganho de peso médio diário (GDP) dos animais, no entanto, pode-se constatar que os animais que receberam ração contendo $0,75 \%$ de lisina apresentaram GPD de 3 a 7,7\% inferior aos demais, sendo os únicos que apresentaram consumo de lisina inferior a $20 \mathrm{~g} /$ dia, o que, associado ao reduzido teor de lisina na proteína total observado neste tratamento $(4,7 \%)$, pode explicar estes resultados.

Estes resultados estão coerentes aos obtidos por MARINHO (1990) e DONZELE et al. (1994), que não observaram efeito dos níveis de lisina sobre o GPD de suínos em terminação. Por outro lado, diferem de outros trabalhos (YEN et al., 1986; LAWRENCE et al., 1994; FRIESEN, et al. 1995; YEN et al., 1996; e SOUZA, 1998).

Os resultados de consumo de ração obtidos neste trabalho concordam com os de outros autores

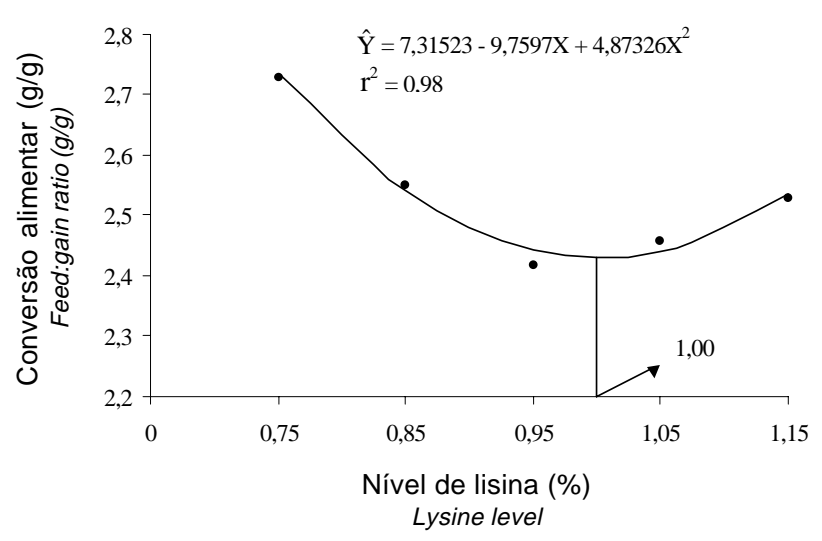

Figura 1 - Efeito do nível de lisina sobre a conversão alimentar de leitoas de 60 a $95 \mathrm{~kg}$.

Figure 1 - Effect of lysine level on feed:gain ratio of gilts from 60 to $95 \mathrm{~kg}$.

(DONZELE et al., 1994; FRIESEN et al., 1995; e SOUZA, 1998), que também não observaram efeito dos tratamentos sobre o consumo de ração de leitões na fase de terminação.

Observou-se efeito $(\mathrm{P}<0,01)$ quadrático dos níveis de lisina sobre a conversão alimentar (CA), que reduziu até o nível de $1,00 \%(0,302 \% / \mathrm{Mcal}$ de ED) (Figura 1), correspondente a um consumo estimado de lisina total de 23,90 g/dia (3,01 g/Mcal de ED) ou $0,90 \%(0,272 \% /$ Mcal de ED) de lisina digestível verdadeira, correspondente a um consumo de lisina digestível de 21,50 g/dia (2,70g /Mcal de ED).

No nível de lisina total $(1,0 \%)$ que proporcionou o melhor resultado de CA, a relação entre os aminoácidos metionina+cistina, treonina, triptofano, valina, isoleucina e a lisina foi de 61, 67, 19, 72 e 59\%, respectivamente. Estes resultados estão de acordo com aqueles referenciados pelo NRC (1998), para suínos de 50 aos $80 \mathrm{~kg}$, de 59, 68, 19,69 e 56\%, para os mesmos aminoácidos, e os obtidos por DONZELE et al. (1994), com leitões dos 60 aos $100 \mathrm{~kg}$ de 59, 67 e $20 \%$ para a relação entre metionina+cistina, treonina e triptofano e a lisina, respectivamente. Por outro lado, os resultados obtidos neste experimento diferem daqueles obtidos por SOUZA (1998), para leitoas na mesma faixa de peso, de 65,63 e $21 \%$. Os valores observados para treonina foram superiores, enquanto os de metionina+cistina e triptofano, inferiores aos encontrados por esse autor. Neste mesmo nível $(1,00 \%)$, a relação entre lisina:proteína total correspondeu a $6,3 \%$, estando coerente com aquele de, aproximadamente, $6,1 \%$ observado por FRIESEN et al. (1994), para leitões de 72 aos $104 \mathrm{~kg}$, que 
FONTES et al.

Tabela 3 - Desempenho, consumo de lisina e nível de uréia no soro sangüíneo de leitoas dos 60 aos $95 \mathrm{~kg}$, em função do nível de lisina da ração

Table 3 - Performance lysine intake, and serum urea level of gilts from 60 to $95 \mathrm{~kg}$, in function of the lysine level of the diet

\begin{tabular}{|c|c|c|c|c|c|c|}
\hline \multirow{2}{*}{$\begin{array}{l}\text { Parâmetro } \\
\text { Parameter }\end{array}$} & \multicolumn{5}{|c|}{ Nível de lisina na ração (\%) } & \multirow{2}{*}{$\begin{array}{l}\mathrm{CV} \\
(\%)\end{array}$} \\
\hline & 0,75 & 0,85 & 0,95 & 1,05 & 1,15 & \\
\hline $\begin{array}{l}\text { Ganho de peso diário }(\mathrm{g}) \\
\text { Daily weight gain }(\mathrm{g})\end{array}$ & 913 & 989 & 982 & 949 & 941 & 8,13 \\
\hline $\begin{array}{l}\text { Consumo de ração diário }(\mathrm{g}) \\
\text { Daily feed intake }(\mathrm{g})\end{array}$ & 2493 & 2523 & 2366 & 2340 & 2372 & 6,50 \\
\hline $\begin{array}{l}\text { Conversão alimentar }{ }^{1}(\mathrm{~g} / \mathrm{g}) \\
\text { Feed/gain ratio }(\mathrm{g} / \mathrm{g})\end{array}$ & 2,73 & 2,55 & 2,42 & 2,46 & 2,53 & 4,02 \\
\hline $\begin{array}{l}\text { Consumo de lisina }(\mathrm{g} / \mathrm{dia})^{2} \\
\text { Lysine intake (g/day) }\end{array}$ & 18,69 & 21,44 & 22,48 & 24,56 & 27,28 & 6,84 \\
\hline $\begin{array}{l}\text { Uréia }(\mathrm{mg} / \mathrm{dL})^{1} \\
\text { Urea }(\mathrm{mg} / \mathrm{dL})\end{array}$ & 35,80 & 33,67 & 30,32 & 27,80 & 32,82 & 6,40 \\
\hline
\end{tabular}

\footnotetext{
1 Efeito quadrático $(\mathrm{P}<0,01)$.

2 Efeito linear $(P<0,01)$.

1 Quadratic effect $(P<.01)$.

2 Linear effect $(P<.01)$.
}

proporcionou melhores resultados de conversão alimentar. Por outro lado, este resultado está acima daqueles referenciados por DONZELE et al. (1994) e SOUZA (1998), de 5,9 e 5,7\%, respectivamente, para leitoas em terminação.

O nível de lisina que proporcionou os melhores resultados de CA dos animais neste trabalho situa-se acima daqueles obtidos por DONZELE et al. (1994), SOUZA (1998) e HAHN et al. (1995), que correspondeu, respectivamente, a 0,$83 ; 0,73 ; \mathrm{e} 0,75 \%$, para leitoas na fase de terminação.

FRIESEN et al. (1995), avaliando níveis de lisina de leitões com alto potencial genético para deposição de carne magra, verificaram que, embora a CA tenha aumentado linearmente com o nível de lisina da ração, a magnitude de melhora na resposta de CA dos animais pareceu pequena entre os tratamentos e, nesse sentido, sugeriram requerimento de lisina de 21 g/dia. Este nível está de acordo com o proposto pelo NRC (1998), 21,1 g/dia de lisina para leitoas com potencial de carne magra, dos 50 aos $80 \mathrm{~kg}$, e estão próximos ao obtido neste experimento de $23,9 \mathrm{~g} / \mathrm{dia}$.

Do mesmo modo que o observado por FONTES et al. (1997), para leitoas dos 30 aos $60 \mathrm{~kg}$, a piora na CA ocorrida entre os últimos dois níveis de lisina avaliados $(1,05$ e $1,15 \%)$ possivelmente esteja relacionado ao custo extra de energia resultante do catabolismo do excesso de aminoácidos, em razão do maior imbalanço, entre eles, naquele nível.

$O$ consumo de lisina aumentou $(\mathrm{P}<0,01)$ de modo linear com o nível de lisina da ração (Figura 2). Têm- se observado respostas semelhantes dos níveis de lisina sobre o consumo de lisina diário em diversos trabalhos (DONZELE et al., 1994; FRIESEN et al., 1995; FONTES et al., 1997; e SOUZA, 1998).

Houve efeito $(\mathrm{P}<0,01)$ quadrático dos tratamentos sobre o teor de uréia no soro sangüíneo dos animais, que reduziu até o nível de 1,00\% de lisina, corroborando os dados obtidos para CA (Figura 3). Este resultado demonstra que o teor de uréia no soro foi uma variável adequada para determinação dos requerimentos de lisina de leitoas na fase de terminação, o que concorda com YEN et al. (1986), COMA et al. (1995) e HAHN et al. (1995).

Os resultados de composição química e das taxas de deposição de proteína e gordura na carcaça, de leitoas dos 60 aos $95 \mathrm{~kg}$, são apresentados na Tabela 4.

Não se observou efeito $(P>0,10)$ dos níveis de lisina sobre a porcentagem de água e proteína e a taxa de deposição de proteína na carcaça, entretanto, constatou-se que a porcentagem de gordura (Figura 4), assim como a taxa de deposição de gordura (Figura 5), reduziu de modo linear $(\mathrm{P}<0,01)$ com o aumento dos níveis de lisina da ração.

Apesar do efeito linear, a porcentagem e a taxa de deposição de gordura foram mínimas, nos valores correspondentes a 16,77\% e 161,62 g/dia respectivamente, no nível de $1,05 \%$ (0,316\%/Mcal de ED) de lisina total ou $0,95 \%(0,286 \% /$ Mcal de ED) de lisina digestível verdadeira, correspondendo a um consumo de lisina total e digestível de 24,56 g/dia (3,17 g/Mcal de ED) e $22,17 \mathrm{~g} / \mathrm{dia}$ (2,85 g/Mcal de ED), respectivamente. 


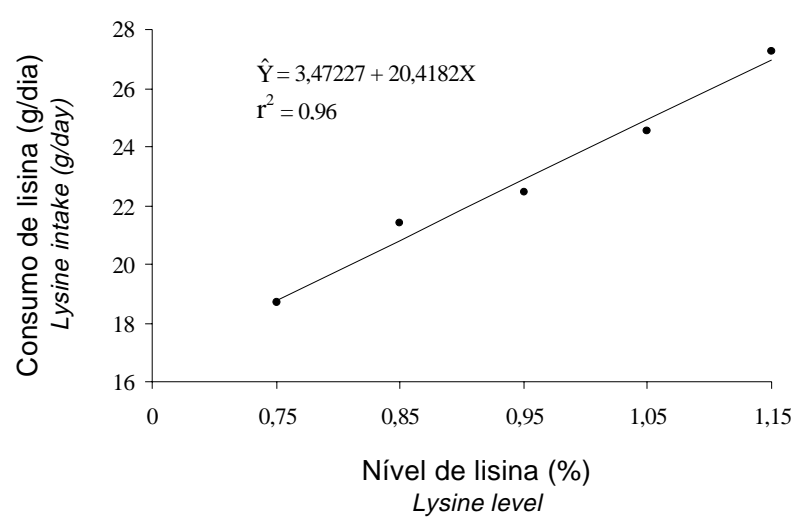

Figura 2 - Efeito do nível de lisina sobre o consumo de lisina de leitoas de 60 a $95 \mathrm{~kg}$.

Figure 2 - Effect of lysine level on lysine intake of gilts from 60 to $95 \mathrm{~kg}$.

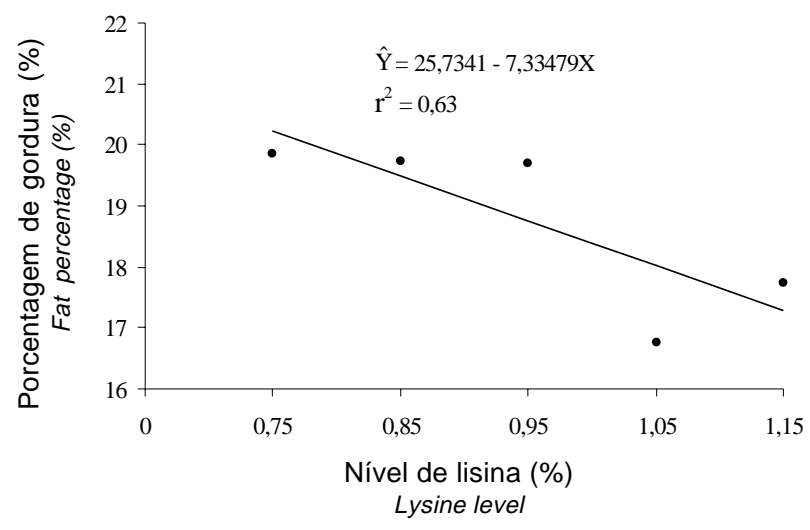

Figura 4 - Efeito do nível de lisina sobre a porcentagem de gordura na carcaça de leitoas de 60 a $95 \mathrm{~kg}$.

Figure 4 - Effect of lysine level on fat carcass percentage of gilts from 60 to $95 \mathrm{~kg}$.

No tratamento correspondente ao nível de 1,05\% de lisina na ração, os conteúdos de proteína e água na carcaça atingiram valores de 17,3 e $62 \%$, respectivamente, sendo que o conteúdo de gordura apresentou valor mínimo de $16,8 \%$. Esses valores, com exceção da água, estão coerentes com os obtidos por FRIESEN et al. (1994), os quais observaram que o conteúdo máximo de proteína e água foi 16,8 e $64,5 \%$, respectivamente, enquanto o conteúdo mínimo de gordura, $16,0 \%$ na carcaça de leitoas, dos 72 aos $104 \mathrm{~kg}$. Estes dados sugerem que o aumento da concentração de lisina na dieta destes animais resultou em alteração na composição do ganho, com redução da porcentagem de gordura na carcaça. Resultados semelhantes fo-

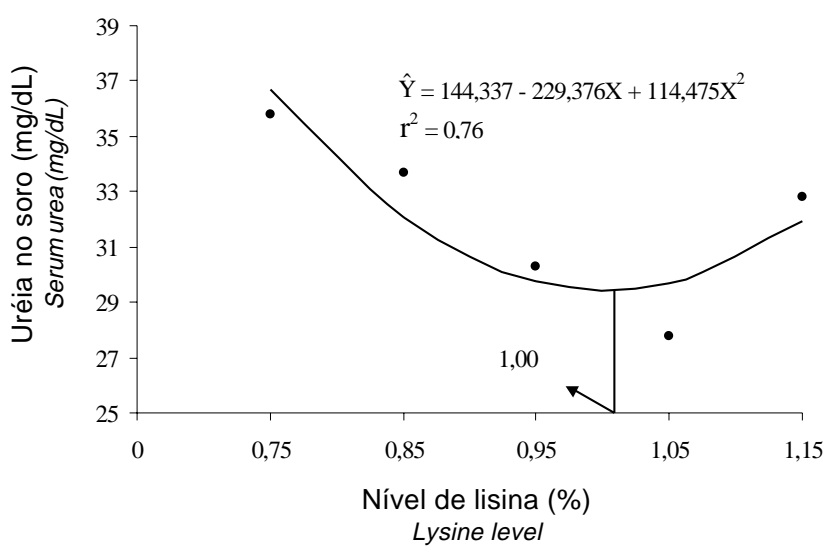

Figura 3 - Efeito do nível de lisina sobre a concentração de uréia no soro sangüíneo de leitoas de 60 a $95 \mathrm{~kg}$.

Figure 3 - Effect of lysine level on the serum urea concentration of gilts from 60 to $95 \mathrm{~kg}$.

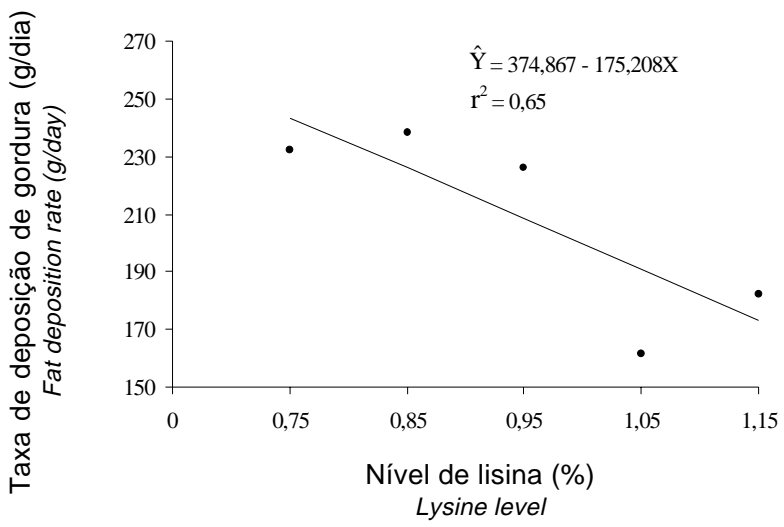

Figura 5 - Efeito do nível de lisina sobre a taxa de deposição de gordura na carcaça de leitoas de 60 a $95 \mathrm{~kg}$.

Figure 5 - Effect of lysine level on carcass fat deposition rate of gilts from 60 to $95 \mathrm{~kg}$.

ram observados com leitoas, da mesma linhagem, dos 30 aos $60 \mathrm{~kg}$.

Os resultados deste estudo, referentes à taxa de deposição de proteína, estão coerentes com os de CAMPBELL et al. (1984), RAO e McCRACKEN, (1990) e YEN et al. (1986), que sugeriram maiores taxas de deposição de proteína para leitoas e machos inteiros em crescimento, nos níveis de lisina entre $22 \mathrm{e}$ 26 g/dia. Do mesmo modo, são semelhantes os dados de LAWRENCEet al. (1994), que, avaliando diferentes relações entre lisina e energia digestível (2,5 a 4,0 g/ Mcal de ED), para suínos machos castrados e leitoas de 50 a $110 \mathrm{~kg}$, sugeriram valores de 3,0 a 3,5 g/Mcal de ED, para suínos alimentados com dietas contendo 
FONTES et al.

Tabela 4 - Composição de carcaça, taxas de deposição de gordura e proteína na carcaça de leitoas entre 60 e $95 \mathrm{~kg}$, alimentados com rações contendo níveis crescentes de lisina

Table 4 - Carcass composition, carcass protein and fat deposition rates of gilts 60 to $95 \mathrm{~kg}$, fed diets with increasing levels of lysine

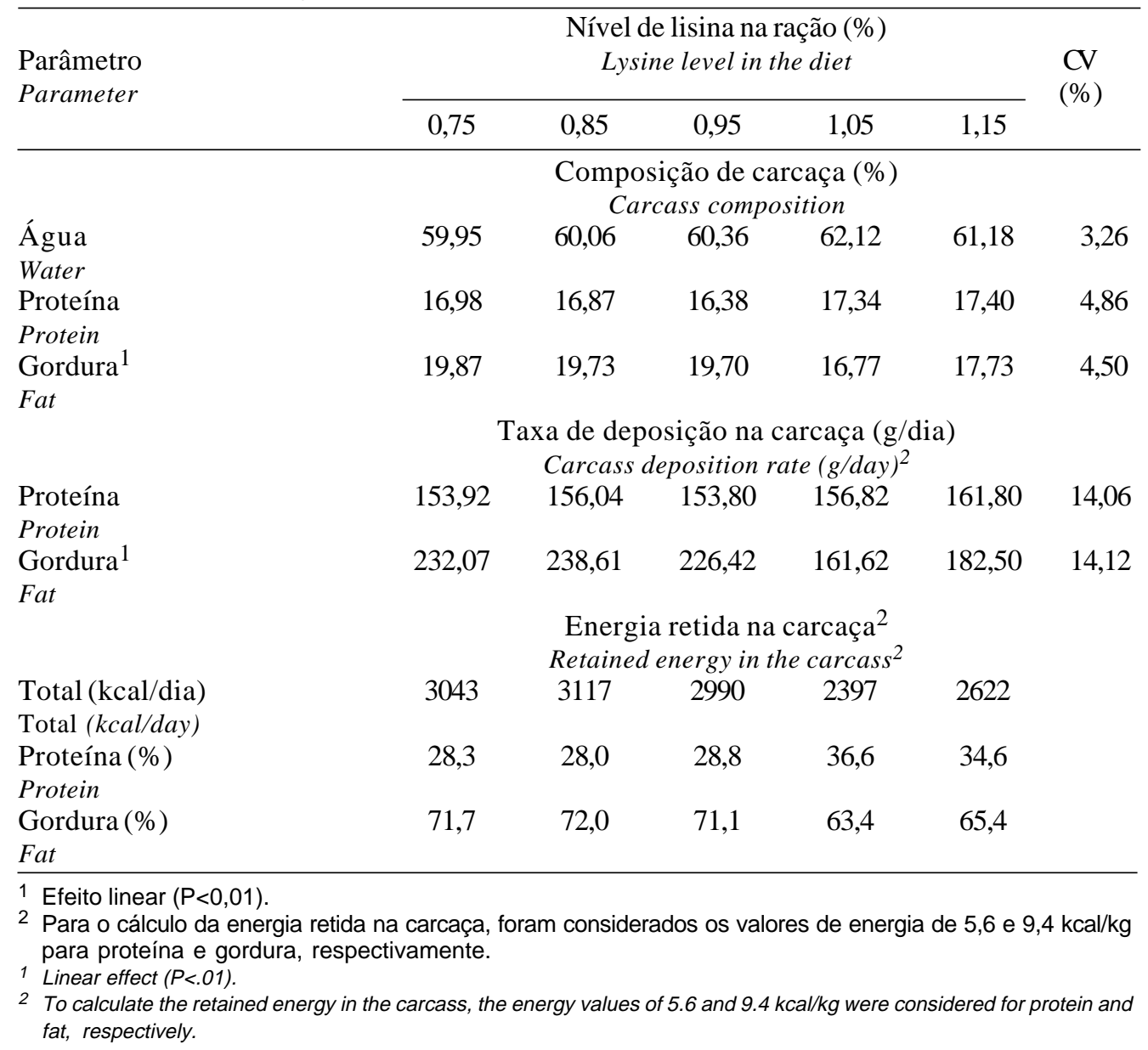

3,5 Mcal de ED/kg, como aqueles que proporcionaram melhores resultados de ganho de peso e deposição de proteína e de carne magra na carcaça.

A taxa de deposição de proteína deste experimento (157 g/dia) foi, em média, semelhante à obtida para os animais de 30 a $60 \mathrm{~kg}(161 \mathrm{~g} / \mathrm{dia})$. Entretanto, FRIESEN et al. (1995) observaram que a taxa de deposição de proteína para leitoas dos 72 aos $136 \mathrm{~kg}$ foi, aproximadamente, $30 \mathrm{~g} /$ dia inferior à de leitoas dos 34 aos 72,5 kg (FRIESEN et al.1994). Segundo esses autores, essas diferenças na taxa de deposição de proteína podem estar relacionadas à baixa resposta à lisina dietética, de determinados grupamentos musculares (músculo longissimus), com o aumento do peso corporal.

Por outro lado, a taxa de deposição de gordura observada neste estudo foi, em média, $25 \%$ superior àquelas observadas para leitoas dos $30 \mathrm{aos} 60 \mathrm{~kg}$. Do mesmo modo, os dados de FRIESEN et al. (1996) revelam que a taxa de deposição de gordura de leitoas dos 34 aos 72,5 kg foi, em média, 48\% inferior à de animais dos 72 aos $136 \mathrm{~kg}$. Estas observações estão de acordo com Sckinckel (1992), citado por FRIESEN et al. (1995), os quais relataram que a taxa de deposição de proteína é normalmente maximizada em suínos entre 40 e $50 \mathrm{~kg}$, entretanto, a taxa de deposição de gordura tende a se elevar com o aumento do peso corporal.

O nível de lisina $(1,00 \%)$ que proporcionou os melhores resultados de CA e teor de uréia no soro $(1,00 \%)$ e aquele que proporcionou os melhores resultados de qualidade de carcaça $(1,05 \%)$ estão acima das recomendações das maiorias das tabelas (ARC, 1981; ROSTAGNO et al., 1983; TABLES AEC, 1987; e NRC, 1998).

O NRC (1998) propõe o nível de 0,81 e $0,76 \%$, para os requerimentos de lisina total e digestível verdadeira, respectivamente, em dietas contendo 3,4 Mcal de ED/kg e $17,1 \%$ de proteína bruta, para 
leitoas com alta capacidade de deposição de carne magra na carcaça, dos 50 aos $80 \mathrm{~kg}$.

Por outro lado, considerando os dados de consumo de lisina diário, os resultados obtidos neste estudo estão coerentes com os obtidos por diversos autores (CROMWELL et al., 1993; OWEN et al., 1994; HANSEN et al., 1994; SUSENBETH et al., 1994; e HAHN et al., 1995), que variaram de 22 a 25,5 g/dia, para suínos em terminação.

Utilizando-se o dado de TDP máxima estimada, na equação proposta pelo ARC (1981) e sugerida por BIKKER e BOSCH (1996), referente ao emprego do modelo fatorial para determinação do requerimento de lisina, estimou-se em $17,12 \mathrm{~g}$ a necessidade de consumo de lisina digestível diário para se obter o melhor desempenho dos animais. Este nível está abaixo do valor de 21,5 g/dia de lisina digestível obtido pelo método tradicional (dose-resposta), que proporcionou os melhores resultados de desempenho. Os resultados obtidos neste estudo permite inferir que o modelo fatorial avaliado pareceu inadequado para estimar o requerimento de lisina digestível de suínos em terminação.

\section{Conclusões}

Concluiu-se que a exigência de lisina total de leitoas dos 60 aos $95 \mathrm{~kg}$ é de $1,00 \%(0,302 \% / \mathrm{Mcal}$ de ED) e $0,90 \%(0,272 \% / M c a l$ de ED) de lisina digestível verdadeira, o que correspondeu a um consumo diário de lisina total e digestível de 23,9 e $21,5 \mathrm{~g}$, respectivamente. O modelo fatorial mostrou-se inadequado para estimar a exigência de lisina digestível desses animais, enquanto o teor de uréia no soro sangüíneo foi efetivo para essa finalidade.

\section{Agradecimento}

À AGROCERES, pela cessão dos animais.

\section{Referências Bibliográficas}

AGRICULTURAL RESEARCH COUNCIL - ARC. 1981. The nutrient requeriments of the pig. Sloug: Commonwealth Agricultural Bureaux. 307p.

BIKKER, P., BOSCH, M. Nutrient requirements of pigs with high genetic potential for lean gain. In: SIMPÓSIO INTERNACIONAL SOBRE EXIGÊNCIAS NUTRICIONAIS DE AVES E SUÍNOS, 1996, Viçosa, MG. Anais...Viçosa: UFV, 1996. CAMPBELL, R.G., TAVERNER, M.R., CURIC. D.M. 1984.
Effect of feeding level and dietary protein content on the growth, body composition and rate of protein deposition in pigs growing from 45 to $90 \mathrm{~kg}$. Anim. Prod., 38:233.

CLOSE, W.H. 1994. Feeding new genotypes: establishing amino acid/energy requirement. In: COLE, D.J.A., WISEMAN, J., VARLEY, M.A. Principles of pig science. Loughborough, U.K.: Nottigham Univ. Press, 1.ed. p.123-140.

COMA, J., CARRION, D., ZIMMERMAN, D.R. 1995. Use of plasma urea nitrogen as a rapid response criterion to determine the lysine requirement of pigs. J. Anim. Sci., 73:472-481.

CROMWELl, G.L., CLINE, T.R., CRENSHAW, J.D. et al. 1993. The dietary protein and (or) lysine requirement of barrows and gilts. J. Anim. Sci., 71:1510-1519.

DONZELE, J.L. FREITAS, R.T.F., OLIVEIRA, R.F.M. et al. 1994. Níveis de lisina para marrãs dos 60 aos $100 \mathrm{~kg}$ de peso vivo. R. Soc. Bras. Zootec., 24(6):959-966.

FONTES, D.O., DONZELE, J.L., CONHALATO, G.S. Níveis de lisina para leitoas com alto potencial genético para deposição de carne magra, dos 30 aos $60 \mathrm{~kg}$. In: REUNIÃO ANUAL DA SOCIEDADE BRASILEIRA DE ZOOTECNIA, 34, 1997, Juiz de Fora, MG. Anais...Juiz de Fora: SBZ, 1997, p.130-132.

FRIESEN, K.G., NELSSEN, J.L., GOODBAND, R.D. et al. 1994. Influence of dietary lysine on growth and carcass composition of high-lean-growth gilts fed from 34 to 72 kilograms. J. Anim. Sci., 72:1761-1770.

FRIESEN, K.G., NELSSEN, J.L., GOODBAND, R.D. et al. 1995. The effect of dietary lysine on growth, carcass composition, and lipid metabolism in high-lean growth gilts fed from 72 to 136 kilograms. J. Anim. Sci., 73:3392-3401.

FRIESEN, K.G., NELSSEN, J.L., GOODBAND, R.D. et al. 1996. The use of compositional growth curves for assessing the response to dietary lysine by high-lean growth gilts. Anim. Sci., 62:159-169.

FULLER, M.F., WANG, T.C. Amino acid requeriments of the growing pig. In: MANIPULATING PIG PRODUCTION. Victoria, 1987. Proceedings... Victoria: APSA, 1987. p.97.

HAHN, J.D., BIEHL, R.R., BAKER, D.H. 1995. Ideal lysine level for early- and late-finishing swine. J. Anim. Sci., 73:773-784.

HANSEN, J.A. NELSSEN, J.L., GOODBAND, R.D. et al. 1994. Interactive effects among porcine somatotropin, the betaadrenergic agonist salbutamol, and dietary lysine on growth performance and nitrogen balance of finishing swine. J. Anim. Sci., 72:1540-1547.

LAWRENCE, B.V., ADEOLA, O., CLINE, T.R. 1994. Lean growth response of pigs fed diets balanced on a lysine to digestible energy basis from 50 to 110. J. Anim. Sci., 72:216 (Suppl. 1).

LOPES, M.A.F., FONTES, D.O., SOUZA, A.V.C. et al. Anastomose íleo-retal em suínos. Técnica de Laplace modificada. In: REUNIÃO ANUAL DA SOCIEDADE BRASILEIRA DE ZOOTECNIA, 35,1998, Botucatu, SP. Anais...Botucatu: SBZ, 1998.

MARINHO, S.F. Exigência nutricional de lisina e avaliação de rações formuladas com valores de lisina total e digestível para suínos em terminação. Viçosa, MG: UFV, 1990. 81p. Dissertação (Mestrado em Zootecnia) - Universidade Federal de Viçosa, 1990.

NATIONAL RESEARCH COUNCIL - NRC. 1988. Committee on Animal Nutrition. Subcommittee of Swine Nutrition. Washington, EUA. Nutrient requirements of swine. 9.ed., Washington, National Academic of Sciences. 93p. 
NATIONAL RESEARCH COUNCIL - NRC. 1998. Committee on Animal Nutrition. Subcommittee of Swine Nutrition. Washington, EUA. Nutrient requirements of swine. 10.ed., Washington, National Academic of Sciences. 189p.

OWEN, K.Q., KNABE, D.A., BURGOON, K.G. et al. 1994. Self-selection of diets and lysine requirements of growingfininshing swine. J. Anim. Sci., 72:554-564.

POZZA, P.C. Exigência de treonina digestível para suínos machos castrados e fêmeas dos 15 a $30 \mathrm{~kg}$. Víçosa, MG: UFV, 1998. 60p. Dissertação (Mestrado em Zootecnia) - Universidade Federal de Viçosa, 1998.

RAO, D.S., McCRACKEN, K.J. 1990. Protein requirements of boars of high genetic potential for lean growth. Anim. Prod., 51:179-187.

ROSTAGNO, H.S., SILVA, D.J., COSTA, P.M.A. et al. 1983. Composição de alimentos e exigências nutricionais de aves e suínos (Tabelas brasileiras). Viçosa, MG: UFV. 59p.

ROSTAGNO, H.S., FEATHERSTON, W.R. 1977. Estudos de métodos para determinação da disponibilidade de aminoácidos. R. Soc. Bras. Zootec., 6(1):64-75.

SILVA, D.J. 1990. Análise de alimentos: métodos químicos e biológicos. 2.ed. Viçosa, MG: UFV. 166p.

SOUZA, A.M. Exigências nutricionais de lisina para suínos mestiços, de 15 a $95 \mathrm{~kg}$ de peso. Viçosa, MG: UFV, 1997. 81p. Dissertação (Mestrado em Zootecnia) - Universidade Federal de Viçosa, 1997.
STAHLY, T.S., CROMWELL, G.L., TERHUNE, D. 1991. Responses of high, medium and low lean growth genotypes to dietary amino acid regimen. J. Anim. Sci., 69:364 (Abstr.) (suppl. 1).

STAHLY, T.S., WILLIAMS, N.H., SWENSON, S. 1994. Impact of genotype and dietary amino acid regimen on growth of pigs from 6 to $25 \mathrm{~kg}$. J. Anim. Sci., 69:165 (suppl. 1).

SUSENBETH, A., SCHNEIDER, R. MENKE, K.H. 1994. The effect of protein and lysine intake on growth and protein retention in pigs. J. Anim. Phisiol. Anim. Nutr., 71:200-207.

TABLES AEC. 1987. Recomendações para nutrição animal. 5. ed. Antony Cedex: Rhône-Poulenc Animal Nutrition. 86p.

UNIVERSIDADE FEDERAL DE VIÇOSA(UFV). 1997. S.A.E.G (Sistemas de Análises Estatísticas e Genéticas). Viçosa, MG (Versão 7.0).

YEN, J.P., KLINDT, J., KERR, B.J. et al. 1996. Lysine requirement in finishing pigs treated with porcine somatotropin by sustainedrelease implant. J. Anim. Sci., 74:196. (suppl. 1).

YEN, H.T., COLE, D.J.A., LEWIS, D. 1986. Amino acid requirements of growing pigs. 7 . The response of pigs from 25 to $35 \mathrm{~kg}$ live weight to dietary ideal protein. Anim. Prod., 43(3):141-154.

Recebido em: 02/02/99

Aceito em: 13/09/99 